\title{
Simultaneous Increases of Extracellular Monoamines in Microdialysates from Hypothalamus of Conscious Rats by Duloxetine, a Dual Serotonin and Norepinephrine Uptake Inhibitor
}

Eric A. Engleman, Ph.D., Kenneth W. Perry, M.S., Douglas A. Mayle, M.S., and David T. Wong, Ph.D.

Duloxetine (LY248686, I + J-N-methyl-3-(1napthalenyloxy)-2-thiophene-propanamine) is a potent dual inhibitor of serotonin (5-hydroxytryptamine, 5-HT) and norepinephrine (NE) uptake in hypothalamus and cerebral cortex of rat brain (Wong et al. 1993; Fuller et al. 1994). Consistent with the dual mechanisms of inhibiting 5-HT and NE uptake, duloxetine at $15 \mathrm{mg} / \mathrm{kg}$ IP produced large increases in extracellular levels of 5-HT $(250 \%)$ and $N E(1,100 \%) 30$ minutes after systemic administration. Levels of 3-methoxy-4-hydroxyphenylethyleneglycol (MHPG) and 5-hydroxyindoleacetic acid (5-HIAA), metabolites of NE and 5-HT, respectively, were reduced, whereas those of dopamine (DA) and its metabolite 3, 4-dihydroxyphenylacetic acid (DOPAC) were not significantly altered. Duloxetine at 7 $\mathrm{mg} / \mathrm{kg}$ produced less pronounced increases while no consistent effects were observed at $4 \mathrm{mg} / \mathrm{kg}$. In this dose range, duloxetine inhibited 5-HT uptake in platelets ex vivo without inhibiting striatal dopamine (DA) uptake. In the present study we also found that the primary amine (a racemate) of duloxetine is about one-fourth as active as duloxetine to inhibit 5-HT and NE uptake. The potential primary amine metabolite of duloxetine might contribute, in part, to the inhibition of 5-HT and NE uptake in vivo. Thus the ability to produce robust increases of extracellular 5-HT and NE levels suggests that duloxetine may potentially be a highly effective antidepressant agent. [Neuropsychopharmacology 12:287-295, 1995]
KEY WORDS: Microdialysis; Hypothalamus; Rats; Monoamines; Uptake inhibitors; High-performance liquid chromatography

Inhibition of presynaptic neurotransmitter uptake should lead to a greater synaptic availability of the targeted neurotransmitter (Fuller and Wong 1990; Geyer

From Lilly Research Laboratories, Eli Lilly and Company, Indianapolis, IN.

Address correspondence to: Dr. Eric A. Engleman, Central Nervous System Research, Eli Lilly and Company, Lilly Corporate Center, Indianapolis, IN 46285

Received August 22, 1994; revised October 31, 1994; accepted November 7, 1994 et al. 1978; Guan and McBride 1988; Marsden et al. 1979). Applications of in vivo techniques (including microdialysis) have demonstrated that extracellular serotonin in most rat brain areas increases several fold over basal levels upon systemic administration of serotonin uptake inhibitors, including fluoxetine (Auerbach et al. 1989; Dailey et al. 1992; Guan and McBride 1988; Perry and Fuller 1992, 1993a; Rutter and Auerbach 1993), indalpine (Kalen et al. 1988), citalopram (Invernizzi et al. 1992), sertraline (Invernizzi et al. 1991), and clomipramine (Adell and Artigas 1991; Carboni and Di Chiara 1989). Extracellular norepinephrine (NE) concentrations are also elevated upon local or peripheral administra- 
tion of the NE uptake inhibitor desipramine (Dennis et al. 1987; Itoh et al. 1990; Kalen et al. 1988; L'Heureux et al. 1986; Thomas and Holman 1991).

Duloxetine (LY248686, [ + ]-N-methyl-3-(1-napthalenyloxy)-2-thiophene-propanamine) is a potent inhibitor of serotonin (5-HT) and NE uptake with inhibitor constants $\left(\mathrm{K}_{\mathrm{i}}\right)$ of $4.6 \pm 1.1$ and $15.6 \pm 2.9 \mathrm{nM}$, respectively, while it is a much weaker inhibitor of dopamine (DA) uptake with a $\mathrm{K}_{\mathrm{i}}$ of $369 \pm 38.1 \mathrm{nM}$ (Wong et al. 1993). It weakly interacts at two to three orders of magnitude higher concentrations with neuronal receptors including 5-HT (1A, 1B, 1C, 1D, 2, and 3), NE $\left(\alpha_{1}, \alpha_{2}\right)$, DA $\left(D_{2}\right)$, muscarinic-acetylcholine, histamine $\mathrm{H}_{1}$, and opiate (Wong et al. 1993).

In the present study we have examined the effects of duloxetine on extracellular monoamines in microdialysates from hypothalamus of conscious rats. Duloxetine dose-dependently elevated concentrations of 5-HT and NE simultaneously in hypothalamus, suggesting greater availability of both monoaminergic neurotransmitters upon concerted inhibition of 5-HT and NE uptake. The present study also shows that the primary amine of duloxetine, a potential metabolite, inhibits 5-HT and NE uptake in vitro and ex vivo with comparable potency to that of duloxetine. Moreover, duloxetine significantly inhibited 5-HT uptake in platelets ex vivo at doses that had no effect on striatal DA uptake ex vivo.

\section{MATERIALS AND METHOD}

\section{Preparation of Synaptosomes for Monoamine Uptake In Vitro}

Male Sprague-Dawley rats (Harlan Industries, Cumberland, IN), weighing 130 to $160 \mathrm{~g}$, were killed by decapitation, the brains removed, and the brain areas immediately dissected on ice. Isolated brain areas were homogenized and suspended in 10 volumes of a medium containing $0.32 \mathrm{M}$ sucrose then centrifuged at $1,000 \mathrm{~g}$ and $4^{\circ} \mathrm{C}$ for 10 minutes. The supernatant was decanted and centrifuged at $17,000 \mathrm{~g}$ for 20 minutes. The resulting synaptosomal pellet $\left(\mathrm{P}_{2}\right)$ was suspended in fresh medium and kept on ice and used later the same day.

\section{Synaptosomal Uptake of ${ }^{3} \mathrm{H}-5-\mathrm{HT}$ and ${ }^{3} \mathrm{H}-\mathrm{NE}$}

Synaptosomal preparations (equivalent to 0.5 to $1.0 \mathrm{mg}$ protein) were incubated at $37^{\circ} \mathrm{C}$ for 5 minutes in 1.0 $\mathrm{ml}$ of Krebs bicarbonate medium containing $10 \mathrm{mM}$ glucose, $0.1 \mathrm{mM}$ iproniazid, $1.0 \mathrm{mM}$ ascorbic acid, $0.17 \mathrm{mM}$ ethylenediamine tetraacetic acid (EDTA), $120 \mathrm{nM}$ ${ }^{3} \mathrm{H}-\mathrm{NE}$ or $50 \mathrm{nM}{ }^{3} \mathrm{H}-5-\mathrm{HT}$, and compounds at five or more concentrations. The reaction mixture was immediately diluted with $2.0 \mathrm{ml}$ of $0.9 \%$ saline and filtered using
Whatman GF/B filters under vacuum with a cell harvester (Brandel, Gaithersburg, MD). Filters were rinsed twice with approximately $5 \mathrm{ml}$ of ice-chilled $0.9 \%$ saline and were transferred to a counting vial containing $10 \mathrm{ml}$ scintillation fluid (PCS, Amersham, Arlington Heights, IL). Radioactivity was measured using a liquid scintillation spectrophotometer. Accumulation of radioactivity at $4^{\circ} \mathrm{C}$ represented background and was subtracted from all samples.

\section{Radiolabeled Ligand Binding}

The $\mathrm{P}_{2}$ pellet was resuspended in 50 volumes of icecold buffer containing $50 \mathrm{mM}$ Tris- $\mathrm{HCl}$ (pH 7.4) and centrifuged at $50,000 \mathrm{~g}$ for 10 minutes. The resulting pellet was again suspended in 50 volumes of ice-cold buffer and incubated at $37^{\circ} \mathrm{C}$ for 10 minutes then centrifuged for 10 minutes at $50,000 \mathrm{~g}$. The pellet was resuspended in 50 volumes of cold buffer and centrifuged at 50,000 $g$ for 10 minutes. The supernatant was discarded, and the remaining pellet was stored at $-70^{\circ} \mathrm{C}$ until use.

Binding of ${ }^{3} \mathrm{H}$-paroxetine and ${ }^{3} \mathrm{H}$-tomoxetine to 5-HT and NE uptake sites, respectively, was carried out in $2 \mathrm{ml}$ of reaction medium containing appropriate drug concentration, $0.1 \mathrm{nM}{ }^{3} \mathrm{H}$-paroxetine or $0.2 \mathrm{nM}$ ${ }^{3} \mathrm{H}$-tomoxetine, and membrane suspension totaling 50 $\mu \mathrm{g}$ protein/tube as previously described (Wong et al. 1993). Nonspecific binding was determined by adding $1.0 \mu \mathrm{M}$ of fluoxetine or desipramine for ${ }^{3} \mathrm{H}$-paroxetine and ${ }^{3} \mathrm{H}$-tomoxetine binding, respectively. Tubes were incubated at $37^{\circ} \mathrm{C}$ for 30 minutes, then filtered through Whatman GF/B filters presoaked for 1 hour with $0.05 \%$ polyethylenimine with a Brandel cell harvester. The filters were washed by rinsing the tubes with cold Tris$\mathrm{HCl}$ buffer ( $\mathrm{pH}$ 7.4). Filters were then placed in scintillation vials, $10 \mathrm{ml}$ of scintillation fluid was added, and radioactivity was measured by liquid scintillation spectrophotometry.

\section{${ }^{3} \mathrm{H}-5-\mathrm{HT}$ Uptake in Rat Platelets and ${ }^{3} \mathrm{H}-\mathrm{DA}$ Uptake in Striatal Homogenates}

After fasting overnight, male Sprague-Dawley rats weighing 115 to $145 \mathrm{~g}$ were dosed with duloxetine or deionized water by oral gavage. One hour later, the rats were sedated by breathing $\mathrm{CO}_{2}$ and blood was collected by cardiac puncture into a syringe containing 1.0 $\mathrm{ml}$ of $3.8 \%$ sodium citrate in normal saline ( $\mathrm{pH} 7.4)$. Rats were quickly decapitated, the brains removed, and various brain regions dissected. Each striatum was homogenized in 10 volumes of $0.32 \mathrm{M}$ sucrose for measurement of ${ }^{3} \mathrm{H}$-DA uptake. Blood samples were centrifuged at $100 \mathrm{~g}$ for 15 minutes at $23^{\circ} \mathrm{C}$. The supernatant containing platelet-rich plasma was recovered, an aliquot taken for platelet concentration determination, and the remainder stored on ice for approximately 1 
hour. A 0.1-ml aliquot was mixed with $2.0 \mathrm{ml}$ Krebs bicarbonate buffer ( $\mathrm{pH} 7.4$ ) containing $10 \mathrm{mM}$ glucose, $0.1 \mathrm{mM}$ iproniazid, $1.0 \mathrm{mM}$ ascorbic acid, $0.17 \mathrm{mM}$ EDTA, and $105 \mathrm{nM}^{3} \mathrm{H}-5-\mathrm{HT}$. Tubes were incubated at $37^{\circ} \mathrm{C}$ for 10 minutes, except the tubes used to represent nonspecific uptake which were kept at $4^{\circ} \mathrm{C}$, after which all tubes were chilled to $4^{\circ} \mathrm{C}$ and $0.1 \mathrm{ml}$ of $20 \%$ formaldehyde was quickly added to each tube to terminate the reaction. Platelets were harvested by filtration through Whatman GF/B filters using a cell harvester (Brandel, Gaithersburg, MD). After rinsing two times with cold normal saline, the filters were transferred to $20-\mathrm{ml}$ scintillation vials, $10 \mathrm{ml}$ of Ready Solv HP scintillation fluid was added, and the vials were counted by liquid scintillation spectroscopy for 5 minutes.

Uptake of ${ }^{3} \mathrm{H}-\mathrm{DA}$ in rat striatal homogenates was performed as described for platelet uptake with the following exceptions: a $0.1-\mathrm{ml}$ aliquot of striatal homogenate was added to $1.0 \mathrm{ml} \mathrm{Krebs} \mathrm{bicarbonate} \mathrm{buffer} \mathrm{with}$ contents listed above except that $110 \mathrm{nM}{ }^{3} \mathrm{H}$-dopamine was substituted for ${ }^{3} \mathrm{H}-5-\mathrm{HT}$, and incubated for 3 minutes at $37^{\circ} \mathrm{C}$. No formaldehyde was added to the tubes.

\section{Microdialysis Assays of Monoamines and Metabolites}

Sprague-Dawley rats (Harlan or Charles Rivers) weighing 270 to $300 \mathrm{~g}$ were surgically implanted with microdialysis probes under chloral hydrate/pentobarbital anesthesia (170 and $36 \mathrm{mg} / \mathrm{kg}$ IP in $30 \%$ propylene glycol, $14 \%$ ethanol) (Perry and Fuller 1992). A David Kopf stereotaxic instrument was used to implant the probe unilaterally in the hypothalamus at coordinates rostral $-1.5 \mathrm{~mm}$, lateral $-1.3 \mathrm{~mm}$, and ventral $-9.0 \mathrm{~mm}$ (Paxinos and Watson 1986). After a 48-hour recovery period, rats were placed in a large plastic bowl with a mounted liquid swivel system (CMA/120 system for freely moving animals; Bioanalytical Systems, West Lafayette, IN). Filtered artificial cerebrospinal fluid (CSF-150 mM $\mathrm{NaCl}, 3.0 \mathrm{mM} \mathrm{KCl}, 1.7 \mathrm{mM} \mathrm{CaCl}_{2}$, and $0.9 \mathrm{mM} \mathrm{MgCl}_{2}$ ) was perfused through the probe at a rate of $1.0 \mu \mathrm{l} / \mathrm{min}$ ute. The output dialysate line was fitted to a high performance liquid chromatography (HPLC) valve.

The HPLC method was similar to that previously described (Perry and Fuller 1992) with some modifica- tions. A 10-port HPLC valve (Valco Instruments, Houston, TX) with a 20- $\mu$ l sample loop was used in a configuration with a small-sample cleanup column (Spherisorb $3 \mu$ ODS2, $2 \times 10 \mathrm{~mm}$, Keystone Scientific, Bellefonte, PA) that trapped late-eluting peaks in the dialysate samples. When the valve was in the inject position, dialysate from the sample loop was injected on to the sample cleanup column and then onto the analytical column (Spherisorb $3 \mu$ ODS2, $2 \times 150 \mathrm{~mm}$, Keystone Scientific, Bellefonte, PA). When the valve was in the load position and dialysate sample was being collected in the sample loop, the sample cleanup column was being backflushed with mobile phase. The valve was in the inject position for 5 minutes and in the load position for 25 minutes with a total run time of 30 minutes.

The mobile phase for both the cleanup and analytical columns was the same and consisted of $75 \mathrm{mM}$ potassium acetate, $0.5 \mathrm{mM}$ EDTA, $1.4 \mathrm{mM}$ sodium octanesulfonic acid and $8 \%$ methanol (pH 4.79). The flow rate for both columns was $0.25 \mathrm{ml} /$ minute, and the analytical column was maintained at $40^{\circ} \mathrm{C}$ while the cleanup column was mounted close to the valve at room temperature. An electrochemical detector (EG\&G PARC, Princeton, NJ) with a dual glassy carbon electrode was used to detect NE, DA, 5-HT, and their metabolites 3-methoxy-4-hydroxyphenylethyleneglycol (MPHG) 3,4-dehydroxyphenylacetic acid (DOPAC), homovanillic acid (HVA), and 5-hydroxyindoleacetic acid (5-HIAA). NE, DA, and 5-HT were assayed at a potential of $350 \mathrm{mV}$, sensitivity setting of $0.5 \mathrm{nA} / \mathrm{V}$, and DOPAC, 5-HIAA, and HVA at a potential of $750 \mathrm{mV}$, sensitivity setting of $50 \mathrm{nA} / \mathrm{V}$. The output of both channels was analyzed and quantitated by a chromatography data system (EZChrom, Scientific Software, San Ramon, CA) on a Compaq 486/33 computer. The sensitivity for NE, 5-HT and DA was approximately 0.1 $\mathrm{pmol} / \mathrm{ml}$ dialysate or $2 \mathrm{fmol}$ injected on to the column. Basal levels were measured for at least 120 minutes prior to drug administration (Table 1).

\section{Drugs}

$\left[{ }^{3} \mathrm{H}\right]-5-\mathrm{HT},\left[{ }^{3} \mathrm{H}\right]-\mathrm{DA},\left[{ }^{3} \mathrm{H}\right] \mathrm{NE}$, and $\left[{ }^{3} \mathrm{H}\right]$-paroxetine were purchased from New England Nuclear Corp. (Boston, $\mathrm{MA})$ and $\left[{ }^{3} \mathrm{H}\right]$-tomoxetine was supplied by Amersham Laboratories (Buckinghamshire, England). Desipramine hydrochloride was obtained from Merrell-National

Table 1. Mean \pm SEM Basal Levels of Monoamines and Their Metabolites in Rat Hypothalamus Dialysates

\begin{tabular}{lcccccrrr}
\hline & \multicolumn{7}{c}{ Compound $(p m o l / m l)(n=6)$} \\
\cline { 2 - 8 } & NE & DA & 5-HT & MHPG & DOPAC & HVA & 5-HIAA \\
\hline Mean & 0.472 & 0.528 & 0.406 & 7.597 & 169.12 & 47.14 & 713.5 \\
\pm SEM & 0.063 & 0.052 & 0.030 & 0.278 & 17.48 & 4.92 & 33.7 \\
\hline
\end{tabular}


Laboratories (Cincinnati, $\mathrm{OH}$ ). Duloxetine, fluoxetine, the racemate of duloxetine $([ \pm]-\mathrm{N}$-methyl-3-(1-napthalenyloxy)-2-thiophene-propanamine), and the primary amine of the duloxetine racemate were synthesized at the Eli Lilly research laboratories (Indianapolis, IN). Drugs used in vivo were prepared in filtered deionized water and administered by IP injection.

\section{Evaluation and Statistical Analyses}

Binding and uptake data were converted to percentages of control, and a Student's $t$-test was used to compare the control with the drug-treated groups. Extracellular levels of the amines and their respective metabolites in microdialysates were calculated by comparing peak heights with those of 50 pmole standards. The mean value of the four samples immediately preceding drug administration served as the basal level for each experiment and data were converted to percentages of basal. Paired $t$-tests were used to compare the mean of the basal values from the time point immediately preceding drug administration to those of each time point thereafter.

\section{RESULTS}

\section{Inhibition of Uptake In Vitro}

Duloxetine, its racemate, and the racemate of its primary amine each inhibited 5-HT and NE uptake in synapotosomes of rat hypothalamus and/or cortex (Table 2 ). Since the positive isomer of the primary amine of duloxetine was not available, the racemate of duloxetine was included for comparison. In hypothalamus duloxetine was the most potent inhibitor of both 5-HT and NE uptake with $K_{i}$ values of $2.4 \pm 0.7$ and $4.1 \pm$ $1.0 \mathrm{nM}$, respectively. The racemate of duloxetine and of its primary amine inhibited 5-HT uptake in hypo-

Table 2. Inhibition of 5-HT and NE Uptake by Duloxetine, Its Primary Amine, and the Racemate of the Primary Amine In Vitro*

\begin{tabular}{|c|c|c|c|}
\hline \multirow[b]{2}{*}{ Compound } & \multirow[b]{2}{*}{ Brain Area } & \multicolumn{2}{|c|}{$\begin{array}{c}\mathrm{K}_{\mathrm{i}}(n M) \\
\text { Inhibition of Uptake }\end{array}$} \\
\hline & & 5-HT & $\mathbf{N E}$ \\
\hline Duloxetine & Hypothalamus & $2.4 \pm 0.7$ & $4.1 \pm 1.0$ \\
\hline Primary amine & $\begin{array}{l}\text { Hypothalamus } \\
\text { Cortex }\end{array}$ & $\begin{array}{l}8.2 \pm 2.4 \\
9.1 \pm 1.7\end{array}$ & $\begin{array}{c}26.0 \pm 6.1 \\
135.2\end{array}$ \\
\hline Racemate & $\begin{array}{l}\text { Hypothalamus } \\
\text { Cortex }\end{array}$ & $\begin{array}{l}6.7 \pm 2.0 \\
5.6 \pm 1.2\end{array}$ & $\begin{array}{c}4.9 \pm 1.2 \\
25.7\end{array}$ \\
\hline
\end{tabular}

* Synaptosomal preparations of cerebral cortex or hypothalamus in duplicate samples were incubated at $37^{\circ} \mathrm{C}$ for 3 minutes in Krebs bicarbonate medium containing seven concentrations (1 to $1,000 \mathrm{mM})$ of the drug tested. thalamus with $\mathrm{K}_{\mathrm{i}}^{\prime} \mathrm{s}$ of $6.7 \pm 2.0$ and $8.2 \pm 2.4 \mathrm{nM}$, respectively, and in cortical synaptosomes with $\mathrm{K}_{\mathrm{i}}$ 's of $5.6 \pm 1.2$ and $9.1 \pm 1.7 \mathrm{nM}$. The potency to inhibit NE uptake by the racemate and the primary amine was five times higher in hypothalamus preparations $\left(\mathrm{K}_{\mathrm{i}}^{\prime}\right.$ 's of 4.9 \pm 1.2 and $26.0 \pm 6.1 \mathrm{nM}$ ) than in cortical preparations ( $\mathrm{K}_{\mathrm{i}}$ 's of 25.7 and $135.2 \mathrm{nM}$, respectively). Duloxetine, a positive isomer, has been shown to inhibit 5-HT and $\mathrm{NE}$ uptake in rat cortical preparations with $\mathrm{K}_{\mathrm{i}}$ values of 4.6 and $15.6 \mathrm{nM}$, respectively (Wong et al. 1993).

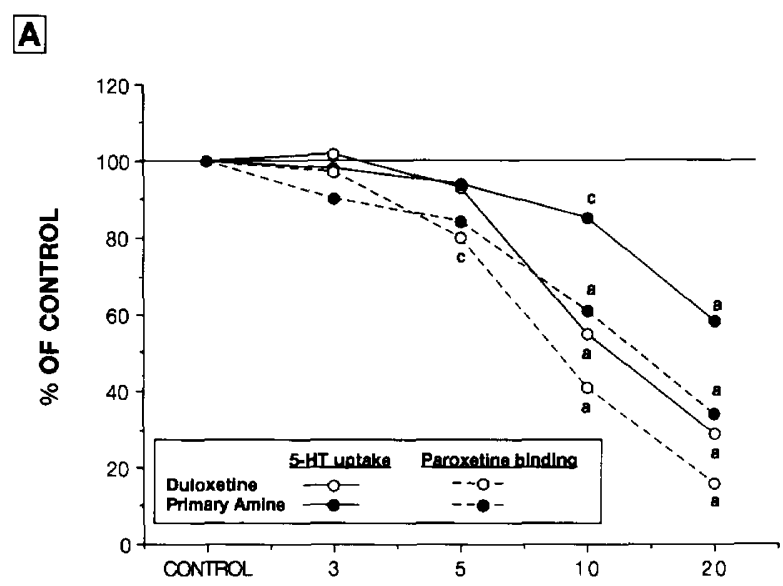

B

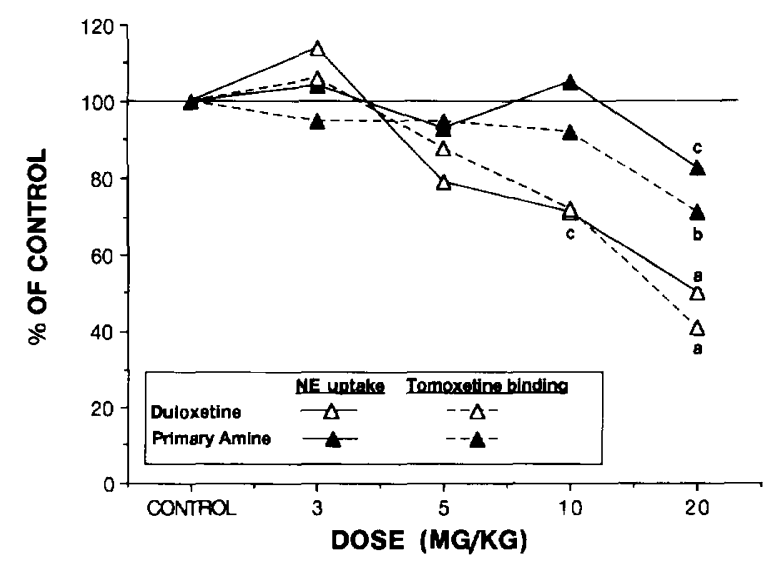

Figure 1. Ex vivo inhibition of uptake and binding in rat hypothalamus: Oral administration of duloxetine or its primary amine dose-dependently inhibited ${ }^{3} \mathrm{H}-5-\mathrm{HT}$ uptake and ${ }^{3} \mathrm{H}$-paroxetine binding (A), as well as ${ }^{3} \mathrm{H}-\mathrm{NE}$ uptake and ${ }^{3} \mathrm{H}$-tomoxetine binding (B), in rat hypothalamus preparations. Uptake: synaptosomes (equivalent to $1.0 \mathrm{mg}$ protein) were incubated in triplicate at $37^{\circ} \mathrm{C}$ for 5 minutes in Krebs bicarbonate buffer ( $\mathrm{pH} 7.4$ ) containing $10 \mathrm{mM}$ glucose, 0.1 $\mathrm{mM}$ iproniazid, $0.2 \mathrm{mg} / \mathrm{ml}$ ascorbic acid, $0.2 \mathrm{mM}$ EDTA, and $0.05 \mu \mathrm{M}^{3} \mathrm{H}-5-\mathrm{HT}$ or ${ }^{3} \mathrm{H}-\mathrm{NE}$. Binding: synaptosomes (equivalent to $0.05 \mathrm{mg}$ protein) were incubated in triplicate at $37^{\circ} \mathrm{C}$ for 30 minutes in $50 \mathrm{mM}$ Tris- $\mathrm{HCl}$ buffer ( $\mathrm{pH}$ 7.4) containing $150 \mathrm{mM} \mathrm{NaCl}, 5.0 \mathrm{mM} \mathrm{KCl}, 0.1 \mathrm{nM}^{3} \mathrm{H}$-paroxetine, or $0.2 \mathrm{nM}$ ${ }^{3} \mathrm{H}$-tomoxetine with or without $1.0 \mu \mathrm{M}$ fluoxetine or desipramine, respectively. 


\section{Inhibition of Uptake Ex Vivo}

Upon administration at $20 \mathrm{mg} / \mathrm{kg} \mathrm{PO}$ in vivo the primary amine of duloxetine inhibited 5-HT and NE uptake ex vivo in rat hypothalamus by $42 \%$ and $17 \%$, respectively, while duloxetine produced a $71 \%$ and $50 \%$ inhibition (Figure 1). Duloxetine or its primary amine compound administered in vivo also dose-dependently inhibited the sodium dependent ${ }^{3} \mathrm{H}$-paroxetine binding to the 5-HT uptake site and ${ }^{3} \mathrm{H}$-tomoxetine binding to the NE uptake site in rat hypothalamus homogenates (Figure 1). After oral administration of duloxetine up to $20 \mathrm{mg} / \mathrm{kg}$, binding of ${ }^{3} \mathrm{H}$-paroxetine and ${ }^{3} \mathrm{H}$-tomoxetine was inhibited by $84 \%$ and $59 \%$, respectively. The primary amine compound inhibited the binding of ${ }^{3} \mathrm{H}$-paroxetine and ${ }^{3} \mathrm{H}$-tomoxetine by $66 \%$ and $29 \%$, respectively (Figure 1).

In a separate study, while there was no significant change in striatal ${ }^{3} \mathrm{H}$-DA uptake over the entire dose range of duloxetine ( 1 to $30 \mathrm{mg} / \mathrm{kg} \mathrm{PO}$ ), ${ }^{3} \mathrm{H}-5-\mathrm{HT}$ uptake in blood platelets ex vivo was dose-dependently inhibited with an $\mathrm{ED}_{50}$ of $7.7 \mathrm{mg} / \mathrm{kg}$ (Figure 2), causing a maximum inhibition of $96 \%$ at the $30-\mathrm{mg} / \mathrm{kg}$ dose.

\section{Monoamines and Metabolites in Microdialysates}

Following sampling for four 30-minute intervals to establish baseline values (Table 1 ), rats were treated with duloxetine $(4,7$, or $15 \mathrm{mg} / \mathrm{kg} \mathrm{IP})$. After administration with the high dose $(15 \mathrm{mg} / \mathrm{kg})$ of duloxetine, extracellular 5-HT and NE levels increased most profoundly by $240 \pm 25 \%$ and $1,100 \pm 380 \%$, respectively, above baseline within the first 30-minute interval (Figures $3 \mathrm{~A}$ and 4A). The elevated levels of 5-HT were maintained significantly above basal levels for up to 3 hours. The elevated NE levels declined to about $800 \%$ in the second 30-minute interval, then gradually decreased fur-

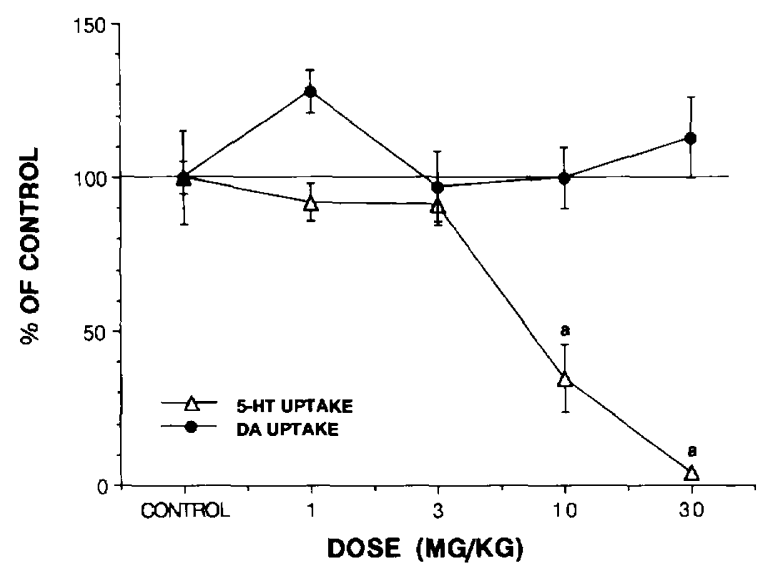

Figure 2. Inhibition of 5-HT and DA uptake by duloxetine. Administration of duloxetine 1, 3, 10, or $30 \mathrm{mg} / \mathrm{kg}$ PO lowered 5-HT uptake in platelets but was without effect on DA uptake in striatal homogenate ex vivo in rats.

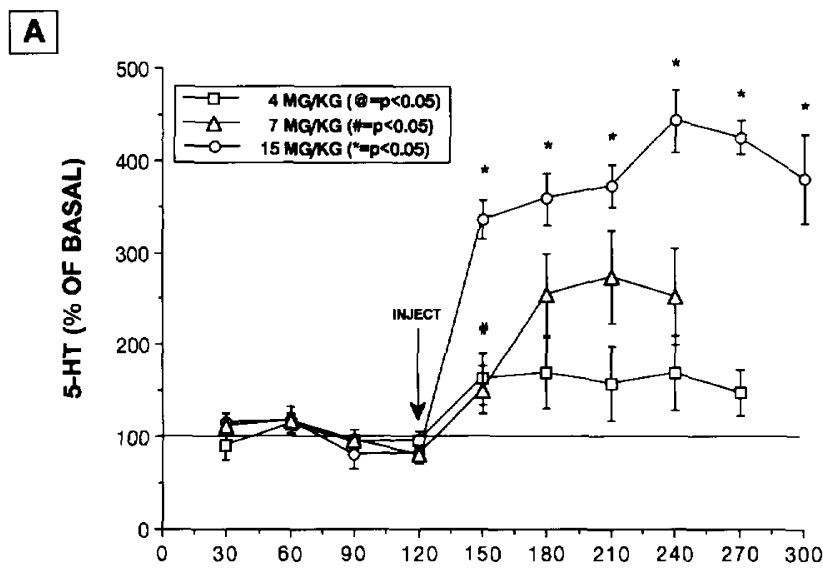

B

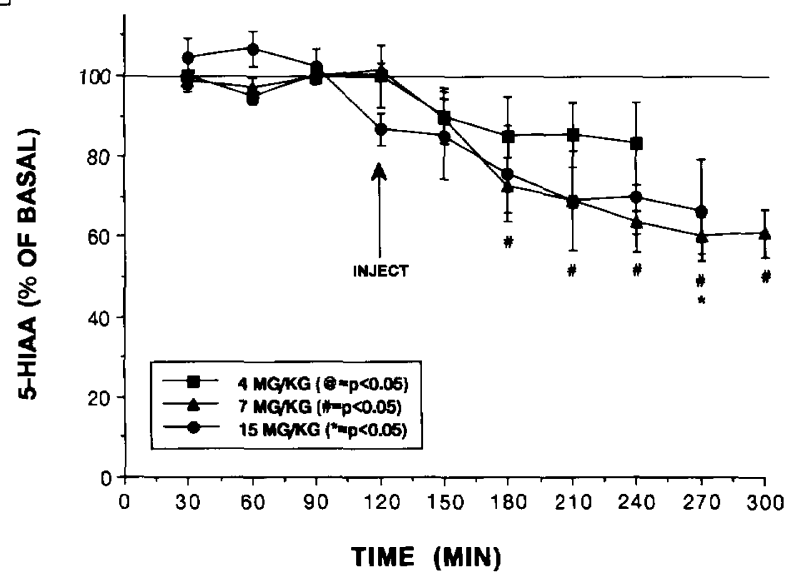

Figure 3. Dose effect of duloxetine on 5-HT and 5-HIAA levels in rat hypothalamus dialysate. Duloxetine at 4, 7, and 15 $\mathrm{mg} / \mathrm{kg}$, IP dose-dependently increases serotonin levels (A) while decreasing 5-HIAA levels (B) in dialysate from rat hypothalamus. Values are in percentages of basal levels (mean \pm SEM for three or more experiments at each dose of duloxetine: * Significantly different from basal at $p<.05$, paired $t$-test.

ther to about $300 \%$ above basal levels 3 hours after administration of duloxetine. No consistent change in levels of DA was observed. However, a trend toward an increase was noted (Figure $5 \mathrm{~A}$ ).

At the $7-\mathrm{mg} / \mathrm{kg}$ dose of duloxetine, extracellular 5 -HT levels gradually rose to $150 \%$ above basal within 1 hour, but this increase did not reach statistical significance (Figure 3A). The increase of NE levels reached nearly $200 \%$ above basal levels in 1 hour, and levels remained significantly elevated for up to 2 hours after administration (Figure 4A). Dialysate levels of 5 -HT, NE, and DA did not vary appreciably from basal values after the 4-mg/kg dose of duloxetine (Figures $3 \mathrm{~A}$, $4 \mathrm{~A}$, and $5 \mathrm{~A}$ ).

After the 7- or $15-\mathrm{mg} / \mathrm{kg}$ doses of duloxetine, 5-HIAA and MHPG levels decreased to $40 \%$ below basal levels (Figures $3 \mathrm{~B}$ and $4 \mathrm{~B}$ ). The DOPAC levels did not 
A

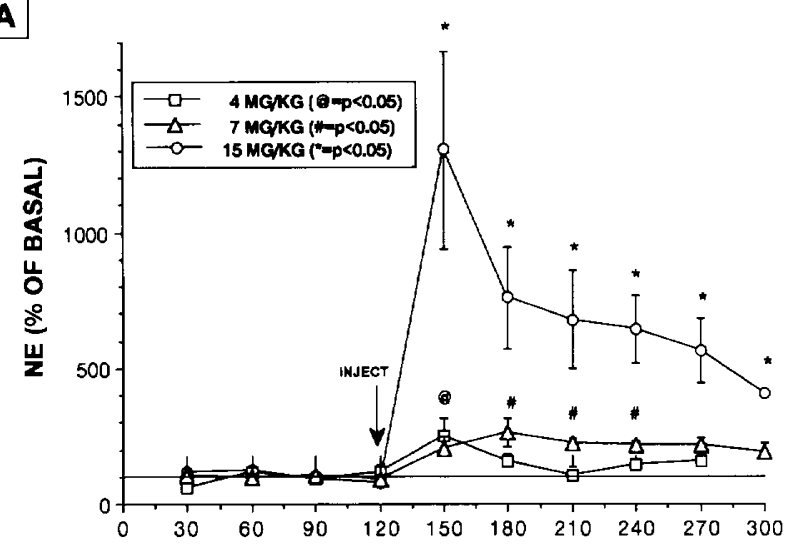

B

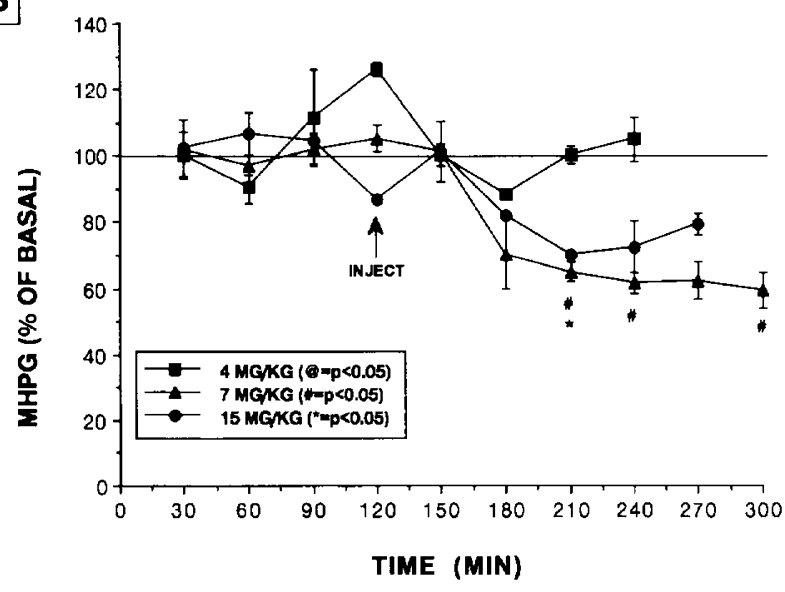

Figure 4. Dose effect of duloxetine on NE and MHPG levels in rat hypothalamus dialysate. Duloxetine at 4,7 , and 15 $\mathrm{mg} / \mathrm{kg}$, IP dose-dependently increases norepinephrine levels (A) while decreasing MHPG levels (B) in dialysate from rat hypothalamus. Values are in percentages of basal levels (mean \pm SEM for at least three experiments at each dose of duloxetine. ${ }^{*}$ Significantly different from basal at $p<.05$, paired $t$-test.

significantly vary from basal levels after administration of duloxetine at 4,7 , or $15 \mathrm{mg} / \mathrm{kg}$ (Figure $5 \mathrm{~B}$ ).

\section{DISCUSSION}

Duloxetine, a secondary amine, potently inhibits 5-HT and NE uptake with a three times greater potency for inhibiting 5-HT uptake. The primary amine of duloxetine is also an effective inhibitor of 5-HT and NE uptake at one-fourth to one-fifth the potency of duloxetine. Thus the potential primary amine metabolite of duloxetine might contribute, in part, to the inhibition of 5-HT and NE uptake in vivo. The potency to inhibit NE uptake by each of these compounds was greater in hypothalamic than cortical preparations and may reflect the higher concentrations of NE uptake carriers in the hypothalamus (Gehlert et al. 1993). Most significantly,
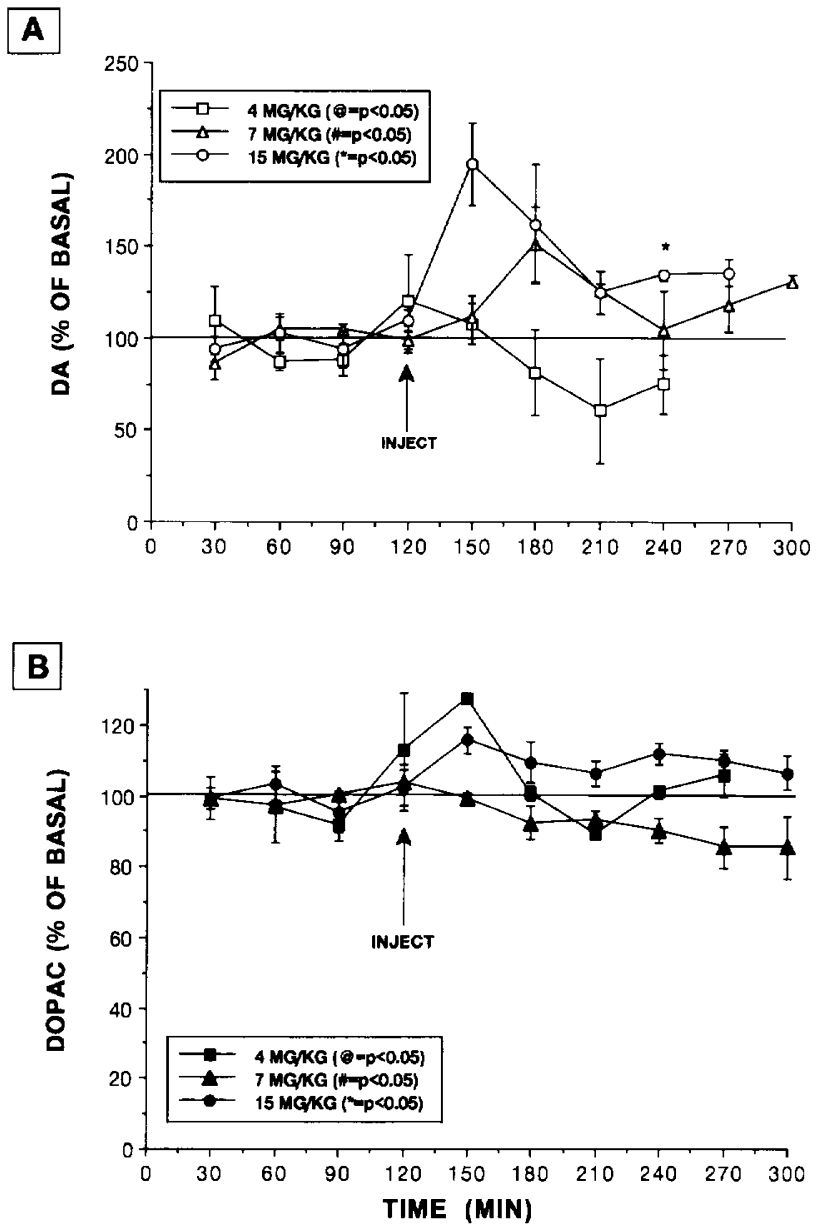

Figure 5. Extracellular levels of DA (A) and DOPAC (B) in hypothalamus as measured by in vivo microdialysis in unanesthetized rats. Duloxetine was administered at 4,7 , or 15 $\mathrm{mg} / \mathrm{kg} \mathrm{IP}$ after at least four 30 -minute periods basal dialysate measurement. Values are presented as percentages of basal values from at least three experiments at each dose of duloxetine. * Significantly different from basal at $p<.05$, paired $t$-test.

the present study shows that duloxetine in vivo produced robust increases in extracellular 5-HT and NE in hypothalamus matching or surpassing the increases elicited separately with other potent inhibitors of 5-HT uptake and inhibitors of NE uptake.

In the current study duloxetine at $15 \mathrm{mg} / \mathrm{kg}$ IP increased extracellular 5-HT to nearly fourfold above the baseline in dialysis samples from hypothalamus. The magnitude of increase after duloxetine treatment was similar to that observed in hypothalamus after the systemic administration of a comparable dose of fluoxetine (Perry and Fuller 1993a). Fluoxetine treatment consistently increased 5-HT levels in most other brain areas: Nearly fourfold in striatum (Perry and Fuller 1992), 2.5fold in thalamus (Dailey et al. 1992), and twofold in diencephalon (Rutter and Auerbach 1993). Among other selective 5-HT uptake inhibitors, indalpine increased 
5-HT levels threefold in caudate-putamen (Kalen et al. 1988). Sertraline (Invernizzi et al. 1991), citalopram (Invernizzi et al. 1992), or clomipramine (Adell and Artigas 1991) produced five-, four-, and threefold increases, respectively, in the raphe areas. However, even after chronic administration of amitriptyline $(10 \mathrm{mg} / \mathrm{kg}$ PO), a putative dual inhibitor of 5-HT and NE uptake, daily for up to 21 days, the extracellular levels of 5-HT in rat frontal cortex were unchanged (Sleight et al. 1989). Acutely, amitriptyline also failed to significantly change 5-HT levels at rat frontal cortex (Kihara and Ikeda 1995). In hypothalamus, however, amitriptyline at $30 \mathrm{mg} / \mathrm{kg}$ IP significantly increased 5-HT levels, although only by 100\% (Engleman and Wong 1994).

An 11-fold increase in extracellular NE levels in hypothalamus microdialysates is most robust among increases of monoamine levels after administration of duloxetine at $15 \mathrm{mg} / \mathrm{kg} \mathrm{IP}$. However, administration of desipramine ( $5 \mathrm{mg} / \mathrm{kg} \mathrm{IP}$ ), a selective inhibitor of NE uptake, produced a fourfold increase in NE levels in rat hypothalamus (Itoh 1990). In other brain areas, desipramine at $10 \mathrm{mg} / \mathrm{kg}$ IP has been shown to elevate NE levels by 2.5-fold in cerebral cortex (L'Heureux et al. 1986) and twofold in thalamus (Yan et al. 1993). Tomoxetine, another selective inhibitor of NE uptake, at the relatively high dose of $20 \mathrm{mg} / \mathrm{kg} \mathrm{SC}$, which is over five times the $E D_{50}$ dose to inhibit NE uptake in vivo (Wong et al. 1982), increased NE levels fourfold in rat hypothalamic microdialysates (unpublished data). Thus, other factors in addition to NE uptake inhibition may contribute to the large increase of NE levels after duloxetine administration at $15 \mathrm{mg} / \mathrm{kg}$ as observed in the present study. The greater availability of 5-HT resulting from the inhibition of 5-HT uptake may contribute to the robust increase of NE concentrations. Indeed, systemic administration of fluoxetine ( $10 \mathrm{mg} / \mathrm{kg} \mathrm{IP})$, a selective serotonin uptake inhibitor, increases not only extracellular 5-HT $(200 \%)$ but also NE levels $(350 \%)$ in hypothalamus (Perry and Fuller 1993a, 1993b). Addition of duloxetine, fluoxetine (unpublished data), or amitriptyline (Engleman and Wong 1994) to the artificial cerebrospinal fluid (CSF) at up to $10 \mu \mathrm{M}$ did not induce the robust increases in NE levels observed with systemic administration of the respective compounds. However, systemic administration of the direct $5-\mathrm{HT}$ agonists 8-hydroxy-2-(di-n-propylamino) tetraline (8-OH-DPAT) Tian et al. 1993) or MK212 (Mayle et al. 1991) increased tissue levels of MHPG-SO ${ }_{4}$ in the hypothalamus indicative of an increase in NE release. Together, these studies suggest a role for 5-HT heteroreceptors located outside of the hypothalamus on NE neurons in increasing extracellular NE levels as observed in the present study. Thus, the concomittant inhibition of 5-HT and NE uptake may afford a greater availability of NE than that resulting from NE uptake inhibition alone.

Milnacipran (Moret et al. 1985) and venlafaxine
(Muth et al. 1986) are both tertiary amines and are also nontricyclic mixed inhibitors of 5-HT and NE uptake. Milnacipran inhibited 5-HT and NE uptake by $50 \%$ $\left(\mathrm{IC}_{50}\right)$ at 203 and $100 \mathrm{nM}$, respectively, while venlafaxine had $\mathrm{IC}_{50}$ values of 210 and $640 \mathrm{nM}$, respectively. However, similar neurochemical studies of milnacipran and venlafaxine using microdialysis techniques have not been reported.

In contrast to the distinct increases in 5-HT and NE levels, no significant increases in DA were observed. Unlike NE and 5-HT, DA metabolite levels (DOPAC) did not decrease after duloxetine. Indeed, at doses up to $30 \mathrm{mg} / \mathrm{kg} \mathrm{IP}$, duloxetine had no effect on DA uptake in striatum ex vivo (Figure 2). These results confirm that duloxetine administration at doses that adequately inhibit 5-HT uptake ex vivo in rat brain or platelets do not inhibit striatal DA uptake ex vivo.

The effects of duloxetine on monoamine levels in the current study support findings from behavioral studies. Duloxetine was shown to dose-dependently suppress food (Wong et al. 1993) and ethanol (Murphy et al. 1989) intake in rats. In mice (Katoh et al. 1993) duloxetine ( 1.6 to $12.5 \mathrm{mg} / \mathrm{kg} \mathrm{PO}$ ) prevented tetrabenazine-induced (50 $\mathrm{mg} / \mathrm{kg} \mathrm{SC}$ ) ptosis and reserpineinduced hypothermia. At 12.5 to $25 \mathrm{mg} / \mathrm{kg}$ PO it induced head movements and tremor when coadministered with 5-hydroxytryptophan ( $100 \mathrm{mg} / \mathrm{kg} \mathrm{IP})$. It also potentiated both clonidine- and morphine-induced analgesia ( 0.6 to $20 \mathrm{mg} / \mathrm{kg} \mathrm{SC}$ ) and attenuated "despair" in forced swimming in mice. In the rat (Katoh et al. 1993) duloxetine ( 12.5 to $25 \mathrm{mg} / \mathrm{kg} P O$ ) significantly decreased REM sleep, but at concentrations up to $200 \mathrm{mg} / \mathrm{kg}$ PO did not affect salivation and lachrymation induced by the cholinergic agonist oxotremorine $(1 \mathrm{mg} / \mathrm{kg} \mathrm{SC})$. These findings demonstrate the behavioral effects of duloxetine resulting from simultaneous NE and 5-HT uptake inhibition and its poor cholinergic activity.

In summary, the data presented in the current study confirm and extend previous neuropharmacological and behavioral studies and demonstrate that duloxetine is a potent dual inhibitor of NE and 5-HT uptake in vivo. The ability of duloxetine to simultaneously increase extracellular levels of NE and 5-HT while not directly interacting with neurotransmitter receptors suggests that duloxetine may be a highly effective antidepressant agent with a low potential for untoward effects.

\section{REFERENCES}

Adell A, Artigas F (1991): Differential effects of clomipramine given locally or systemically on extracellular 5-hydroxytryptamine in raphe nuclei and frontal cortex. An in vivo brain microdialysis study. Naunyn Schmiedebergs Arch Pharmacol 343:237-244

Auerbach SB, Minzenberg MJ, Wilkinson LO (1989): Extracellular serotonin and 5-hydroxyindoleacetic acid in hypo- 
thalamus of the unanesthetized rat measured by in vivo dialysis coupled to high-performance liquid chromatography with electrochemical detection: Dialysate serotonin reflects neuronal release. Brain Res 499:281-290

Carboni E, Di Chiara G (1989): Serotonin release estimated by transcortical dialysis in freely-moving rats. Neuroscience 32:637-645

Dailey JW, Yan QS, Mishra PK, Burger RL, Jobe PC (1992): Effects of fluoxetine on convulsions and on brain serotonin as detected by microdialysis in genetically epilepsyprone rats. J Pharmacol Exp Therap 260:533-540

Dennis T, L'Heureux R, Carter C, Scatton B (1987): Presynaptic alpha-2 adrenoceptors play a major role in the effects of idazoxan on cortical noradrenaline release (as measured by in vivo dialysis) in the rat. J Pharmacol Exp Therap 241:642-649

Engleman EA, Wong DT (1994): Profound increases in extracellular hypothalamic norepinephrine concentrations after systemic administration of amitriptyline. Soc Neurosci Abstr 20:383

Fuller RW, Hemrick-Luecke SK, Snoddy HD (1994): Effects of duloxetine, an antidepressant drug candidate, on concentrations of monoamines and their metabolites in rats and mice. J Pharmacol Exp Ther 269:132-136

Fuller RW, Wong DT (1990): Serotonin uptake and serotonin uptake inhibition. Proc NY Acad Sci 600:68-78

Gehlert DR, Gackenheimer SL, Robertson DW (1993): Localization of rat brain binding sites for $\left[{ }^{3} \mathrm{H}\right]$ tomoxetine, an enantiomerically pure ligand for norepinephrine reuptake sites. Neurosci Lett 157:203-206

Geyer MA, Dawsey WJ, Mandell AL (1978): Fading: A new cytofluorimetric measure quantifying serotonin in the presence of catecholamines at the cellular level in brain. J Pharmacol Exp Ther 207:650-667

Guan XM, McBride WJ (1988): Fluoxetine increases the extracellular levels of serotonin in the nucleus accumbens. Brain Res Bull 21:43-46

Invernizzi R, Belli S, Samanin R (1991): An increase of extracellular serotonin in the dorsal raphe masks the effect of sertraline in the frontal cortex. In Rollema $\mathrm{H}$, Westerink BHC, Drijfhout WJ (eds), Monitoring Molecules in Neuroscience, Meppel, The Netherlands, Krips Repro, pp 253-255

Invernizzi R, Belli S, Samanin R (1992): Citalopram's ability to increase extracellular concentrations of serotonin in the dorsal raphe prevents the drug's effect in the frontal cortex. Brain Res 584:322-324

Itoh $Y$, Oishi R, Nishibori M, Saeki K (1990): In vivo measurement of noradrenaline and 3, 4-dihydroxyphenylethyleneglycol in the rat hypothalamus by microdialysis: Effects of various drugs affecting noradrenaline metabolism. J Pharmacol Exp Ther 255:1090-1097

Kalen P, Strecker RE, Rosengren E, Bjorklund A (1988): Endogenous release of neuronal serotonin and 5-hydroxyindoleacetic acid in the caudate-putamen of the rat as revealed by intracerebral dialysis coupled to high-performance liquid chromatography with fluorimetric detection. J Neurochem 51:1422-1435

Katoh A, Eigyo M, Ishibashi C, Naitoh Y, Takeuchi M, Ibii N, Ikeda M, Matsushita A, Leander DJ (1993): Behavioral and electroencephalographic properties of duloxetine
(LY248686) in mice and rats. Am Coll Neuropsychopharmacol 32:165

Kihara T, Ikeda M(1995): Effects of duloxetine, a new serotonin and norepinephrine uptake inhibitor on extracellular monoamine levels in rat frontal cortex. J Pharmacol Exp Ther 272:177-183

L'Heureux R, Dennis T, Curet O, Scatton B (1986): Measurement of endogenous noradrenaline release in the rat cerebral cortex in vivo by transcortical dialysis: Effects of drugs affecting noradrenergic transmission. J Neurochem 46:1794-1801

Marsden CA, Conti J, Strope E (1979): Monitoring 5-hydroxytryptophan release in the brain of freely moving unanesthetized rat using in vivo voltametry. Brain Res 171:85-99

Mayle DA, Robertson DW, Wong DT (1991): Elevation of catecholaminergic metabolite levels in the rat hypothalamus by an agonist of serotonin 1C/2 receptors, MK212 (6-chloro-2-(1-piperazinyl)pyrazine). Soc Neurosci Abstr 17:407

Moret C, Charveron M, Finberg PM, Couzinier JP, Briley M (1985): Biochemical profile of midalcipran (F 2207), 1-phenyl-1-diethyl-aminocarbonyl-2-aminomethyl-cyclopropane $(Z)$ hydrochloride, a potential fourth generation antidepressant drug. Neuropharmacol 24:1211- 1219

Murphy JM, McBride WJ, Lumeng L, Li T-K, Wong DT (1989): Suppression of alcohol and food intake by LY 264453, a new inhibitor of serotonin (5-HT) and norepinephrine (NE) uptake. Abstract Soc Neurosci 15:58

Muth EA, Haskins JT, Moyer JA, Husbands GEM, Nielsen ST, Sigg EB (1986): Antidepressant biochemical profile of the novel bicyclic compound WY-45,030 and ethylcyclohexanol derivative. Biochem Pharmacol 35:4493-4497

Paxinos G, Watson C (1986): The Rat Brain in Stereotaxic Coordinates, London, Academic Press

Perry KW, Fuller RW (1992): Effect of fluoxetine on serotonin and dopamine concentration in microdialysis fluid from rat striatum. Life Sci 50:1683-1690

Perry KW, Fuller RW (1993a): Extracellular 5-hydroxytryptamine concentration in rat hypothalamus after administration of fluoxetine plus L-5-hydroxytryptophan. J Pharm Pharmacol 45:759-761

Perry KW, Fuller RW (1993b): A method for the simultaneous assay of norepinephrine, dopamine, and serotonin and their metabolites in rat hypothalamic microdialysates. Soc for Neurosci Abstr 19:1174

Rutter JJ, Auerbach SB (1993): Acute uptake inhibition increases extracellular serotonin in the rat forebrain. J Pharmacol Exp Ther 265:1319-1324

Sleight AJ, Smith RJ, Marsden CA, Palfrexman MG (1989): The effects of chronic treatment with amitriptyline and MDL 72394 on the control of 5-HT release in vivo. Neuropharmacology 28(5):477-480

Tian Y, Eaton JJ, Goudreau JL, Lookingland KJ, Moore KE (1993): Neurochemical evidence that 5-hydroxytryptaminergic neurons tonically inhibit noradrenergic neurons terminating in the hypothalamus. Brain Res 667: 215-221

Thomas DN, Holman RB (1991): A microdialysis study of the regulation of endogenous noradrenaline release in the rat hippocampus. J Neurochem 56:1741-1746 
Wong DT, Threlkeld PG, Best KL, Bymaster FP (1982): A new inhibitor of norepinephrine uptake devoid of affinity for receptors in rat brain. J Pharm Exp Ther 222:61-65

Wong DT, Bymaster FP, Mayle DA, Reid LR, Krushinski JH, Robertson DW (1993): LY248686, a new inhibitor of ser- otonin and norepinephrine uptake. Neuropsychopharmacol 8:23-33

Yan QS, Jobe PC, Dailey JW (1993). Noradrenergic mechanisms for the anticonvulsant effects of desipramine and yohimbine in genetically epilepsy-prone rats: Studies with microdialysis. Brain Res 610:24-31 